\title{
La expansión del podcast en la radio pública: estudio comparado de Radio Nacional Argentina y Radio Nacional de España (2019)
}

\author{
María del Pilar Martínez-Costa \\ Universidad de Navarra \\ marcosta@unav.es \\ https://orcid.org/0000-0002-6564-0207
}

\author{
María José Müller \\ Universidad Austral, Argentina \\ mmuller@austral.edu.ar \\ https://orcid.org/0000-0003-2870-3261
}

\author{
Marta VilLar \\ Universidad Austral, Argentina \\ mavillar@austral.edu.ar \\ https://orcid.org/0000-0001-5859-433X
}

\section{The podcast expansion in public radio: comparative study of Radio Nacional Argentina and Radio Nacional de España(2019)}

\section{RESUMEN ABSTRACT}

La radio pública se enfrenta al desafío de seguir cumpliendo su misión de servicio con las reglas y oportunidades que ofrece el entorno digital para innovar en el contenido y en el modo de alcanzar a las nuevas audiencias. El podcast resulta un formato sonoro que se adapta muy bien a estos tiempos de audiencias diversificadas y con intereses específicos. Esta investigación estudia la oferta de podcast de la radio pública de cobertura nacional en Argentina y España, y con ello persigue delimitar su papel en la ampliación del repertorio de contenidos de la radio tradicional en un entorno de crecimiento de la producción y consumo de audio. Se utiliza la metodología del análisis de contenido para describir y comparar la oferta de podcast de LRA1 y Radio 1, las emisoras

generalistas de Radio Nacional Argentina y Radio Nacional de España, respectivamente; y así evaluar en qué grado su implantación fortalece su misión de servicio público.

PALABRAS CLAVE

Radio; Radio pública; podcast; Innovación radiofónica; Radio servicio
Public radio faces the challenge of continuing to fulfill its service mission with the rules and opportunities offered by the digital environment to innovate in contents and audiences. The podcast is a sound format that adapts very well to these times of diversified audiences and with specific interests. This research studies the podcast offer of the national public coverage radio in Argentina and Spain, and with it seeks to define its role in order to expanding the repertoire of traditional radio content in an environment of production and consumption growth of audio. The content analysis methodology is used to describe and compare the podcast offer of LRA1 and Radio 1, the full service stations of Radio Nacional Argentina and Radio Nacional de España, respectively; and thus evaluate to what extent its implementation strengthens its public service mission.

KEYWORDS

Broadcast Radio, Public Radio; Podcast;

Radio Innovation; Service Radio 


\section{Introducción}

En la mayoría de los mercados radiofónicos del mundo la radio pública siempre ha sido un referente en la promoción de valores como el pluralismo, la identidad cultural y la diversidad. Para muchas de estas emisoras, el valor de la innovación también ha resultado, como mínimo, una aspiración que ha guiado sus producciones, con resultados más o menos exitosos. Ante los desafíos que el entorno digital propone a la radio, las emisoras públicas también decidieron explorar las posibilidades que la digitalización ofrece para el desarrollo de contenidos de interés público.

El formato del podcast - contenido de audio digital bajo demanda, del que se habla desde 2004, pero que ha crecido especialmente en los últimos dos añosresulta una forma atractiva de distribuir lo que ya ofrece la antena y, a su vez, de producir más contenidos solo para la red. El podcast permite empaquetar de modo asincrónico sus contenidos y ofrecerlos a demanda a un usuario selectivo y orientado a consumir lo que es verdaderamente de su interés. Es un modo cada vez más sencillo y económico de ampliar la oferta y el público, y así adaptarse a los nuevos consumos. La radio pública también necesita encontrar caminos alternativos para seguir ofreciendo contenidos de calidad, diversos y representativos de sus culturas a través de las nuevas formas que reclama el entorno digital.

En este trabajo se propone analizar la oferta de podcast de las emisoras públicas generalistas de Argentina y España: LRA1, de Radio Nacional Argentina (RNA) y Radio 1, de Radio Nacional de España (RNE). A través de un análisis de contenido se estudia la oferta de podcast de ambas emisoras con el objetivo de responder las siguientes preguntas de investigación: ¿Qué oferta de podcast tienen las radios públicas generalistas de cobertura nacional de los países estudiados? ¿Qué tipos de podcast se producen? ¿Qué estrategia adopta la radio pública en la producción de podcast? ¿Cuáles son los canales de distribución digital utilizados? ¿Qué tipo de géneros y temas predominan en los podcasts de la radio pública? ¿Qué principios de la radio pública impulsan el diseño y producción de podcast?

\section{Radio pública e innovación}

La radio pública nació bajo la convicción de que un recurso escaso -como lo eran en sus inicios las frecuencias de radio- debía ser de titularidad estatal para asegurar su utilización en interés del público. Según los países, dicha titularidad estatal permitía o limitaba la gestión de las emisoras a los particulares, fueran empresas privadas comerciales o instituciones sin ánimo de lucro. En el caso europeo, la escasez inicial de frecuencias justificó el establecimiento de monopolios públicos de radiodifusión: organismos autorizados que, o bien formaban parte de la estructura del gobierno de turno, o bien se establecieron como corporaciones de derecho público, pero con autonomía económica y política (Martínez-Costa, 1995, p.113).

No fue el caso de la mayoría de los países de América Latina y de España, donde -aunque el Estado mantenía el control de la distribución y reparto de frecuencias - la gestión y explotación de las emisoras de radio se delegó en sus inicios a los particulares. En estos países, la radio pública nace bien avanzados los años treinta del siglo $X X$, cuando se comprueba la importancia de la radio como medio de comunicación de masas y la necesidad de asegurar coberturas en todo el territorio de un país.

En cualquier caso $-y$ siguiendo el modelo de radio pública implantado por el primer director general de la BBC, John Charles Walsham Reith (Briggs, 1961, p.235) - se construyó un concepto de radio pública comprometida con los valores sociales y culturales de su comunidad, accesible a toda la población, representativo de toda su diversidad y con una programación de calidad. Una radio pública cuyo papel es defender las industrias y las identidades nacionales, que convive con la radio privada comercial y la radio privada no comercial, también llamada comunitaria o asociativa (Lewis y Booth, 1992). Este espíritu se ha mantenido a lo largo de las décadas, subrayando su papel en la dinamización de la vida pública, tanto cultural como informativa, y en la preocupación por hacer una radio de calidad (World Radio and Television Council, 2001, p.7).

En un contexto de abundancia de sistemas, soportes y plataformas de distribución de señales de radio y televisión como el digital actual, la radio pública ha centrado su razón de ser en la atención y promoción de los valores cívicos y culturales, la pluralidad informativa, la atención y defensa de los todos los grupos sociales en especial los vulnerables y minoritarios-, así como el impulso de la experimentación y la innovación en el sector de las tecnologías de la comunicación.

Este último aspecto es el que interesa abordar en este estudio. Más concretamente, el papel de la radio pública de alcance nacional en la innovación tecnológica y narrativa de la radio, en un momento de la historia de la comunicación en que la producción y el consumo de 
audio crecen a gran velocidad en diferentes soportes y formatos.

El podcast resulta un formato que responde a este principio de innovación y que, en consecuencia, la radio pública adoptó bastante pronto. En los primeros tiempos se trataba de programas de la radio tradicional o de fragmentos de éstos que, luego de ser emitidos en directo, se ponían a disposición en la red para la descarga posterior. En mayo de 2005 la BBC ofreció sus primeros podcasts, que fueron los programas más destacados de Radio 4. En agosto del mismo año, NPR hizo lo propio y en sólo 6 días "Story for the day" se convirtió en el primer podcast en descargas de Itunes. A su vez, ese mes la palabra podcast fue una de las más buscadas en el sitio NPR.org (Niles, 2005) y el Oxford American Dictionary seleccionó el término como el vocablo del año 2005 (Wired, 2005).

En el contexto de la irrupción del podcasting en España (Moreno, Martínez-Costa y Amoedo, 2009; Gallego, 2010; Pérez y Gallego, 2012), Radio Nacional de España (RNE) comienza en 2008 a ofrecer bajo demanda los programas de la antena y algunos programas culturales y de ficción de su emisora Radio 3. Tuvo que pasar más de una década para que, a partir de 2019, ofreciera además una oferta nativa de podcast, es decir, un repertorio de contenidos diseñados originalmente para su distribución digital. Por su parte, Radio Nacional Argentina (RNA) ofrece audio de la antena bajo demanda de forma intermitente y esporádica hasta que en 2018 lanza una oferta mixta de podcast nativos y no nativos a través de su web.

Como se observa, aunque la relación entre la radio pública y la oferta asincrónica de audio se inicia de forma temprana, durante muchos años no se aprovechó el potencial del podcast como herramienta de innovación. Las emisoras se limitaron a ofrecer a la carta el sonido y la programación de antena, fragmentando su oferta tradicional en una selección de podcast no nativos, y sin aprovechar las posibilidades de ampliar la oferta programática a través de los podcasts nativos, diseñados y creados para su difusión digital a demanda.

En esos los primeros pasos del podcasting, la radio pública tuvo la oportunidad de convertirse en "propulsora de un nuevo modelo de comunicación entre la radio y su audiencia, como garante de servicio público, profundizando más en las peculiaridades y nuevas transformaciones que origina su presencia en Internet, alejado del concepto de radio tradicional" (Martínez y Salgado, 2009, p.47). Se trataba de dar el paso para hacer compatibles una radio lineal, de programación en continuidad, generalista o especializada, pero homogénea; y una radio no lineal, centrada en el catálogo, los nichos de audiencias, la experimentación y la heterogeneidad (Bonet y Sellas, 2019). Sin embargo, el proceso de cambio de la industria de la radio, tanto pública como privada, frente al nuevo escenario ha demostrado ser lento y con ciertas resistencias, desaprovechando, incluso, los altos niveles de credibilidad del medio (Pérez-Alaejos, Pedrero-Esteban y Leoz-Aizpuru, 2018, pp.92-93).

La radio pública tiene aún más responsabilidad, si cabe, que las emisoras comerciales en la exploración de las nuevas narrativas que permite el podcasting (García-Marín y Aparici, 2018), sin descuidar la relevancia y la calidad de sus contenidos, orientados tanto a las grandes audiencias como a las audiencias de nicho. A este respecto, Pedrero Esteban y García Lastra-Núñez plantean que la radio debe proyectar en este entorno "el incalculable valor de su archivo sonoro, explorar el potencial narrativo que brindan los canales online, abundar en la extensión hipertextual y transmedia de sus piezas, y exprimir las opciones interactivas de las nuevas herramientas de distribución, pero sin descuidar la irrenunciable relevancia al elegir y diseñar sus contenidos, la eterna base de su producto, el secreto de su resiliencia y el emblema de su centenaria marca" (2019, p.29). Además de la diversificación de contenidos y la fragmentación de audiencias, el podcasting facilita la proliferación de productores independientes que no necesitan de grandes inversiones para crear sus propios contenidos (Espada, 2018; Orrantia, 2019). En este sentido, Berry (2016, p.17) habla de la desprofesionalización y descentralización del proceso productivo, uno de los mayores cambios que incorpora el formato, frente al broadcasting. Esta nueva realidad permite a las radios tradicionales de carácter público experimentar coproducciones con organizaciones de la sociedad civil, con otros organismos públicos o con ciudadanos independientes, y así explorar nuevos caminos para conseguir una mayor representatividad y participación de grupos minoritarios y heterogéneos.

\section{Metodología}

\subsection{Los casos de estudio}

Para estudiar y analizar la oferta de podcast de la radio pública y evaluar en qué grado su implantación fortalece su misión de servicio público innovador y de calidad se han seleccionado dos casos de estudio: las emisoras generalistas de Radio Nacional Argentina y Radio Nacional de España. El estudio de caso es una herramienta de investigación cuyo objetivo es conocer y comprender de manera inductiva la particularidad de una situación. A partir de la observación y recolección de datos concre- 
tos se pueden establecer hipótesis o teorías generales. Este método de investigación es útil cuando las preguntas principales de investigación son "cómo" y "por qué", cuando el investigador es un observador externo, y cuando el foco de estudio es un fenómeno contemporáneo (Yin, 2014).

\subsubsection{Radio Nacional Argentina (RNA)}

Radio Nacional Argentina (RNA) comenzó sus transmisiones el 6 de julio de 1937', convirtiéndose en la primera emisora argentina dependiente del gobierno nacional. En la actualidad, es una unidad de negocio de Radio y Televisión Argentina S.E. (RTA), empresa que integra el servicio de radiodifusión argentino compuesto por la red de 49 emisoras de RNA en todo el territorio nacional, el servicio de Radiodifusión Argentina al Exterior (RAE), la Televisión Pública Argentina y el Canal 12 de Trenque Lauquen, provincia de Buenos Aires.

RTA S.E. se constituye como tal a través de la Ley de Servicios de Comunicación Audiovisual, en concreto, se refiere a ella el Título 7 sobre los Servicios de Radiodifusión del Estado Nacional, en sus artículos 119 al $123^{2}$. Allí se establece la creación de la empresa con esa denominación, la legislación aplicable como empresa y sociedad del Estado, los objetivos, las obligaciones y la programación. La reglamentación de esta normativa se desarrolla a través del decreto 1.526/2009³ que establece las previsiones necesarias para el funcionamiento de Radio y Televisión Argentina Sociedad del Estado. Entre los objetivos y las obligaciones se indica que los servicios de radiodifusión pública "deben respetar y promover el pluralismo político, religioso, social, cultural, lingüístico y étnico"; así como "promover el desarrollo y la protección de la identidad nacional, en el marco pluricultural de todas las regiones (...), promover la producción de contenidos audiovisuales propios y contribuir a la difusión de la producción audiovisual regional, nacional y latinoamericana".

LRA 1 es la emisora generalista de RNA. En la actualidad, no cuenta con mediciones de audiencia desde que en abril de 2018 se diera de baja del servicio de Kantar lbope Media, porque no hacía mediciones representativas de todo el país. No obstante, la industria radiofónica reconoce que RNA no ocupa los primeros puestos de audiencia en la Argentina, que están destinados a las emisoras comerciales desde hace décadas.

RNA ha intentado muchas veces ser un medio del Estado más que un medio gubernamental, dependiente del gobierno de turno, pero nunca lo ha conseguido. En algunas oportunidades pretendió copiar alguno de los modelos de medios públicos de Europa o Estados Unidos, otras veces intentó emular a los medios comerciales, pero siempre terminó siendo una radio gubernamental.

En 2001 RNA comenzó con los primeros ensayos de emisión en streaming, mucho antes de tener su plataforma de contenidos online. En marzo de 2017 lanzó formalmente el área de podcasts y así generó un espacio dedicado a empaquetar lo producido en la radio tradicional. Durante ese año también trabajó en la producción de programas exclusivos para la red, que se emitieron por primera vez en 2018. Aunque el área de podcast de la radio pública argentina no tiene aún mucho recorrido, está dando resultados fructíferos. La escucha y la descarga de estos contenidos crece al ritmo que lo hace la producción de nuevos episodios. Incluso puede decirse que hoy RNA es una de las emisoras que lidera la oferta de podcast en Argentina, que es escasa o nula en el resto del mercado de la radio.

Hasta la llegada de los podcasts y la posibilidad de empaquetar de modo asincrónico los contenidos de la radio tradicional, la radio pública no había puesto tanto foco en el streaming y en la escucha de contenidos bajo demanda. En la actualidad, hay un departamento de la radio pública que trabaja en el rearmado y reempaquetado de los programas de la antena y su adecuación a la red, así como en la producción de nuevos podcasts nativos.

\subsubsection{Radio Nacional de España (RNE)}

Radio Nacional de España (RNE) fue fundada el 19 de enero de $1937^{4}$, en plena Guerra Civil Española, ligada a los objetivos del bando denominado nacional. En la actualidad es la empresa pública que se encarga de la gestión directa del servicio público de radiodifusión en España. Está compuesta de cuatro emisoras de radio que abarcan el territorio nacional, además de Ràdio 4 en Cataluña y el servicio internacional de Radio Exterior de España. Forma parte de la Corporación de Radio y Televisión española S.A. (CRTVE), sociedad mercantil estatal que organiza la gestión indirecta del servicio público de radio y televisión de España, creada en 2007 cuando se reestructura y redefine el hasta entonces denominado Ente Público Radiotelevisión Española.

En la actualidad, la gestión de la radio y la televisión pública se rige en España por el criterio de servicio público recogido en la Ley 17/2006, que específicamente garantiza los "valores de pluralismo, veracidad y accesibilidad con el fin de contribuir a la formación de una opinión pública informada" y prevé la organización y el control parlamentario de los medios de comunicación social dependientes del Estado, que se incluyen en el artículo 20 de la Constitución española ${ }^{5}$. Dicha ley dio lugar en 2007 al mandato-marco que despliega las 
características del servicio y enumera entre sus objetivos y fines el ofrecer una programación radiofónica "que se adecue a la evolución social y a las expectativas y demandas de la sociedad española" y que esté "presente en los medios o soportes tecnológicos derivados del desarrollo de la Sociedad de la Información"6, haciendo uso de todos los canales disponibles y ratificando su vocación y apuesta por la innovación.

En este contexto jurídico, la emisora pública generalista del grupo es Radio Nacional de España, también denominada Radio 1. Es la cuarta emisora de radio de su tipo más escuchada del país con 1.139 .000 oyentes semanales, según la 3a oleada del Estudio General de Medios de 2019 (AIMC, 2019).

A lo largo de su historia, Radio Nacional de España ha entendido la producción de obras radiofónicas innovadoras y de calidad como parte de su vocación pública. Tiene una dilatada experiencia en la producción de formatos de ficción y documentales que, la implantación de la web, primero, y el auge del consumo de audio bajo demanda, después, no ha hecho más que incrementar. Desde 2008 la emisora pública, que ya tenía grandes obras en su archivo sonoro, impulsa el desarrollo del radioteatro a través de "Ficción sonora", cuyas producciones se emiten en la antena y están luego disponibles en la red. A partir de 2011 se suma la oferta de contenidos transmedia y de podcast del Laboratorio de RTVE y RNE, un área de innovación y creatividad audiovisual dentro del departamento de Estrategia y Desarrollo de Negocios de Medios Interactivos de la Corporación, que ha dado lugar a producciones binaulares y ficciones sonoras inmersivas.

En abril de 2019, RNE lanza "Solo en podcast", que presenta la oferta de podcast nativos de ficción, información y experimentación de la radio pública. Así, la oferta de audio digital de RNE se alimenta de cuatro vías: la redifusión de contenidos no nativos producidos para la radio tradicional ("Radio a la carta"), el acceso al archivo sonoro histórico ("Archivo sonoro"), las producciones de ficción sonora ("Ficción sonora") y la oferta exclusiva de podcast nativos ("Solo en podcast").

\subsection{La selección de la muestra y el diseño del análisis de contenido}

Una vez identificados y descritos los casos de estudio, se ha aplicado la metodología del análisis de contenido para recolectar los datos, describir la oferta de podcast y proceder al estudio de sus características. Bardin (1996) define el análisis de contenido como el conjunto de técnicas tendentes a obtener indicadores sistemáticos y objetivos que describan el contenido de un mensaje, permitiendo la inferencia de caracterizaciones relativas a sus condiciones de producción.

\subsubsection{Identificación de la muestra y de las variables de estudio}

Para desarrollar el análisis de contenido se ha seleccionado una muestra compuesta por las series de podcast que publicaron las emisoras generalistas de Radio Nacional Argentina, LRA1, y de Radio Nacional de España, Radio 1, entre el 4 y el 11 de octubre de 2019. En el caso argentino, se trata de 29 series, con sus correspondientes episodios, en total 3.219 podcasts. En el mismo sentido, se consideraron las 73 series de RNE disponibles en ese período, que suman 145.826 podcasts. Aun tratándose de universos de diferente tamaño, este es un primer estudio exploratorio, no exhaustivo, para identificar tendencias en una selección de estos podcasts.

La unidad de análisis es el episodio y se ha procedido a la escucha del último episodio publicado de cada una de las series de podcast de ambas emisoras, que suponen una muestra de 102 podcast y 74 horas de audios. Se entiende que dadas las estructuras homogéneas de los episodios de una misma serie, la escucha y codificación del último publicado resulta una referencia suficiente y representativa como muestra exploratoria. Sobre esta muestra, se aplicó una matriz de análisis con 4 grupos de variables: aspectos formales, características de la producción, recursos narrativos y principios o valores.

\begin{tabular}{|c|c|}
\hline Programa & Géneros \\
\hline \multirow{3}{*}{ Ficción } & $\begin{array}{l}\text { Adaptaciones literarias, } \\
\text { cinematográficas }\end{array}$ \\
\hline & Radioteatro/radio relatos \\
\hline & Humor \\
\hline \multirow{4}{*}{$\begin{array}{l}\text { No Ficción } \\
\text { - Informativos y de } \\
\text { opinión de actuali- } \\
\text { dad }\end{array}$} & Noticias \\
\hline & Comentarios \\
\hline & Magacín \\
\hline & Entrevista \\
\hline \multirow{3}{*}{$\begin{array}{l}\text { - Entretenimiento } \\
\text { - Formativos/divulga- } \\
\text { tivos/interés social }\end{array}$} & $\begin{array}{l}\text { Mesa redonda, debate o } \\
\text { tertulia }\end{array}$ \\
\hline & Reportaje \\
\hline & Documental \\
\hline
\end{tabular}

Tabla 1. Tipos de programas y géneros. Elaboración propia.

Entre los aspectos formales se han registrado los datos de cada serie, como nombre y enlace, duración, cantidad de episodios publicados y periodicidad. En cuanto a la duración, se ha estudiado si se trata de una extensión variable en cada edición de las diferentes series o si resulta una duración común a todos los episodios. A su vez, la periodicidad se ha definido según 5 tipos: 
diaria, semanal, de fin de semana, mensual o variable. En cuanto a las características de la producción, se ha tenido en cuenta el origen de la producción (propia, coproducción, de terceros o externalizada) y el tipo de producción (nativa si es exclusiva para podcast y no nativa si su origen es la antena tradicional). Entre los recursos narrativos se ha estudiado el tipo de programa (ficción o no ficción) y, según esta primera clasificación, se determinaron los géneros utilizados, como figura en la Tabla 1.

También dentro de los recursos narrativos se han incluido las temáticas que abordan las emisoras en sus podcasts. En este caso, se ha tenido en cuenta la clasificación que utiliza en sus informes anuales el Digital News Report, que incluye 12 categorías temáticas y que puede verse en la Tabla 2

\begin{tabular}{|l|l|}
\hline \multirow{4}{*}{ Soft News } & Arte y cultura \\
\cline { 2 - 3 } & Estilos de vida \\
\cline { 2 - 3 } & Entretenimiento y famosos \\
\hline \multirow{4}{*}{ Hard News } & Deportivas \\
\hline & Negocios y economía \\
\hline & Salud y educación \\
\hline & Sucesos, judiciales y de seguridad \\
\hline & Medioambientales \\
\hline & Internacionales \\
\cline { 2 - 3 } & Ciencia y tecnología \\
\hline & Políticas \\
\hline & Regionales o locales \\
\hline
\end{tabular}

Tabla 2. Clasificación de noticias según sus temáticas. Digital News Report, 2016.

A esta clasificación se incorporó posteriormente la categoría temática "historia", ya que al hacer el estudio se comprobó que las emisoras públicas abordan con frecuencia esta temática.

Por último, la matriz incorpora el registro y análisis de los valores o principios propios de la radio pública por los que se vela en sus contenidos bajo demanda. Según un relevamiento que se hizo de los documentos legales de las emisoras estudiadas, fueron seleccionados los principios que aparecen con más frecuencia en la definición de estructura legal y su misión pública, y que son: identidad cultural, pluralismo, diversidad cultural, igualdad de género y atención a minorías. Para medir los valores en la producción de podcast, se analizó la cantidad de veces que los cinco principios antes mencionados aparecen en las distintas series.

\subsubsection{Descripción de los valores y principios de la radio pública estudiados}

La radio pública, con un fundamental rol de servicio, siempre ha trabajado sobre la base de unos principios o valores que la distinguen de las emisoras comerciales y que la rigen para determinar sus pautas de producción y de relación con la audiencia. Las emisoras públicas comparten muchos de estos principios rectores, aunque su formulación adquiere características particulares y se adaptan a los cambios sociales, culturales o tecnológicos.

Para establecer qué principios se identificarían como variables a estudiar en las series de podcast analizadas en este trabajo, se revisó la legislación de RNA y RNE y se seleccionaron los principios más recurrentes en sus textos. En el caso argentino, se estudió la única ley que regula el funcionamiento de los medios, que es la Ley 26.522/2009, conocida como la Ley de Servicios de Comunicación Audiovisual, ya referenciada, que fue modificada por el decreto $267 / 2016$, pero sin afectar las disposiciones relativas a medios públicos y valores de servicio público. Se consideró además el punto 16 de los principios elaborados en consenso por el sector de los medios y telecomunicaciones para la creación de una ley de comunicaciones emergentes en 2016 ?

En el caso español, se analizaron la Ley 17/2006 de la Radio y la Televisión de Titularidad Estatal, que desarrolla el artículo 20 de la Constitución española y el mandato-marco de la Corporación RTVE previsto en el artículo 4 de la Ley 17/2006, mencionados en epígrafes anteriores. Se analizaron también la ley 7/2010, conocida como Ley General de la Comunicación Audiovisual ${ }^{8}$, y el documento "Principios básicos de la programación de RTVE"'.

Tras este análisis de los textos, se seleccionaron los cinco valores y principios que definen la misión de la radio pública que se mencionan con más frecuencia en estos documentos, y que se definen a continuación.

\subsubsection{Pluralismo}

La Real Academia Española define al pluralismo como "el sistema por el cual se acepta o reconoce la pluralidad de doctrinas o posiciones". En tanto que el diccionario jurídico de la RAE describe al pluralismo como el "derecho de todas las personas a que la comunicación audiovisual se preste a través de una pluralidad de medios, tanto públicos, como comerciales o comunitarios, que reflejen el pluralismo ideológico, político y cultural de la 
sociedad". Allí también se lo menciona como "el derecho a que la comunicación audiovisual se preste a través de una diversidad de fuentes y de contenidos y a la existencia de diferentes ámbitos de cobertura, acordes con la organización territorial del Estado".

El pluralismo informativo y cultural constituye un valor fundamental para los medios de comunicación desde su existencia. En todas las legislaciones mencionadas se establece la misión de dar voz a todos los sectores sociales en las programaciones de radio. Se considera que una emisión es plural si permite que distintas posiciones ideológicas puedan expresarse. Así se convierte en un valor fundamental al que deben aspirar todos los medios de comunicación de una sociedad democrática y, en particular, los medios públicos.

La Ley de Servicios de Comunicación Audiovisual de 2016 de Argentina, en el artículo 21 inciso b, señala que las empresas públicas de radiodifusión deben "respetar y promover el pluralismo político, religioso, social, cultural, lingüístico y étnico". Por su parte, el artículo 3, inciso b, de la Ley 17/2006 de España, se encomienda al servicio público de radio y televisión "garantizar la información objetiva, veraz y plural, que se deberá ajustar plenamente al criterio de independencia profesional y al pluralismo político, social e ideológico presente en nuestra sociedad, así como a la norma de distinguir y separar, de forma perceptible, la información de la opinión".

\subsubsection{Diversidad cultural}

En el artículo 1 de la Declaración Universal de la UNESCO sobre la Diversidad Cultural se define dicha diversidad como un patrimonio común de la humanidad:

La cultura adquiere formas diversas a través del tiempo y del espacio. Esta diversidad se manifiesta en la originalidad y la pluralidad de las identidades que caracterizan a los grupos y las sociedades que componen la humanidad. Fuente de intercambios, de innovación y de creatividad, la diversidad cultural es tan necesaria para el género humano como la diversidad biológica para los organismos vivos. En este sentido, constituye el patrimonio común de la humanidad y debe ser reconocida y consolidada en beneficio de las generaciones presentes y futuras (UNESCO, 2001).

Por su parte, la Unión Europea de Radiodifusión (UER/ EBU) ha hecho su declaración de valores centrales para los medios públicos estableciendo seis aspectos fundamentales. Entre ellos, establece el valor de la diversidad, garantizada a través de la pluralidad informativa y cultural (EBU, 2012).

En las legislaciones sobre medios públicos españoles y argentinos también se subraya la importancia de la diversidad cultural. En el caso de la corporación de RTVE la normativa actual establece que debe asegurarse la máxima cobertura geográfica, social y cultural e impulsar la diversidad cultural y lingüística en toda su oferta digital. En la norma argentina, por su parte, se permite por parte del Estado la creación de conglomerados de producción que garanticen la diversidad cultural en las producciones audiovisuales que, aunque no obliga directamente a Radio Nacional Argentina, expresa el espíritu general de las indicaciones de la UNESCO.

\subsubsection{Identidad cultural}

La identidad cultural como valor de política pública está ligada al surgimiento y desarrollo de la radiodifusión. Según el tesauro de la UNESCO, la identidad cultural es la correspondencia que existe entre una comunidad (nacional, étnica, lingüística, etc.) y su vida cultural, así como el derecho de cada comunidad a mantener su propia cultura (UNESCO, 2019). Murciano subraya que los servicios públicos de radiodifusión de ámbito nacional permiten hacer efectivos y defender los principios y derechos básicos constitucionalmente reconocidos, como lo son la diversidad, la identidad cultural, la independencia industrial y comercial, el fomento de la vida asociativa y ciudadana y la protección y bienestar de la infancia y juventud (2006, p. 380-381).

La misión de preservación de la identidad cultural se advierte claramente en el mandato que tienen tanto RNE como RNA y que está explicitado en el artículo 3 de la ley 17/2006 española y en los artículos 1, 3, 9 y 65 de la ley argentina. En dicha normativa se subraya la importancia de promover la industria cultural, artística y educativa autóctona, local y regional y, en el caso español, también la difusión del castellano y las lenguas cooficiales.

\subsubsection{Igualdad de género}

Entre los indicadores UNESCO de cultura para el desarrollo, y recogiendo documentos anteriores de la Organización de Naciones Unidas, se menciona y define la igualdad de género como "la igualdad de derechos, responsabilidades y oportunidades de las mujeres y los hombres, y las niñas y los niños" (UNESCO, 2014).

En la legislación analizada también se menciona específicamente este punto. Por ejemplo, en la Ley 26.522/2009 argentina se plantea en el artículo 3, punto m: "Promover la protección y salvaguarda de la igualdad entre hombres y mujeres, y el tratamiento plural, 
igualitario y no estereotipado, evitando toda discriminación por género u orientación sexual". Mientras que en la Ley española 17/2006 en el artículo 3, punto 2, inciso k, se establece que los servicios de radiodifusión públicos deben "fomentar la protección y salvaguarda de la igualdad entre hombre y mujer, evitando toda discriminación entre ellos".

\subsubsection{Atención a minorías}

La referencia a minorías incluye a los grupos sociales que se encuentran en menor proporción en las naciones y gozan del derecho de protección por sus respectivas normativas. En el caso del encuadre legal de las radios públicas tanto en la Argentina como España se identifican menciones explícitas para promover la presencia en el espacio público de estos grupos.

En la legislación argentina se establece que se prestará atención a la inclusión de minorías, especialmente a los pueblos originarios y a la accesibilidad para discapacitados. En este último punto se refiere sobre todo a recursos que deben implementar para hacer accesible los contenidos audiovisuales a disminuidos visuales $\mathrm{e}$ hipoacúsicos, a través de la inclusión en sus contenidos de audio descripción o lenguaje de señas.

En la ley española 17/2006, cuando se describe la misión del medio público, se especifica en el artículo 3, punto 2 , inciso j que la Corporación RTVE "debe apoyar la integración social de las minorías y atender a grupos sociales con necesidades específicas". Además, en el artículo 11 del mandato-marco menciona de manera más detallada que la "oferta programática pondrá especial cuidado para que ninguna persona pueda ser discriminada o vejada por razones de edad, discapacidad, etnia, raza, creencia o religión, orientación sexual o condición social".

\section{Resultados}

En el momento de hacer el estudio, RNA tenía publicadas 29 series, que suman un total de 3.219 episodios. La mayoría de estas producciones proceden de la antena tradicional y son rempaquetadas para la red. Sólo 3 series, y sus correspondientes 22 episodios, son contenidos exclusivos para ser consumidos en formato podcast: "Nos", "Ser iguales" y "Nosotros, que fuimos a Malvinas".

Por su parte, RNE tenía publicadas 73 series de podcast que suman un total de 145.826 episodios. La mayoría son fragmentos editados de los tramos más significativos de los programas que se emiten en antena y que, en su versión podcast, nunca superan la hora. Son muy pocos los programas de la antena que se publican completos en su versión podcast. A su vez, sobre el total de las producciones analizadas (73), solo 7 son nativas digitales y se ofrecen en la sección "Solo en podcast" de la web: "Ficciones sonoras binaurales", "Litercast", "Vivir Gaza", "Soñadores", "Mi vida es un cliffhanger", "Un bonito cadáver", "Soy mujer... soy autista". Tiene además una serie que se titula "Biblioteca Pública", que se emite exclusivamente vía web desde 2013.

Desde el punto de vista del origen de la producción, los podcasts de RNE son todas producciones propias. Mientras que RNA cuenta con 27 (de 29) series de producción propia, 1 coproducción ("Una vuelta al mundo") y un programa de terceros que es de Radio Sputnik ("Vivir en Rusia").

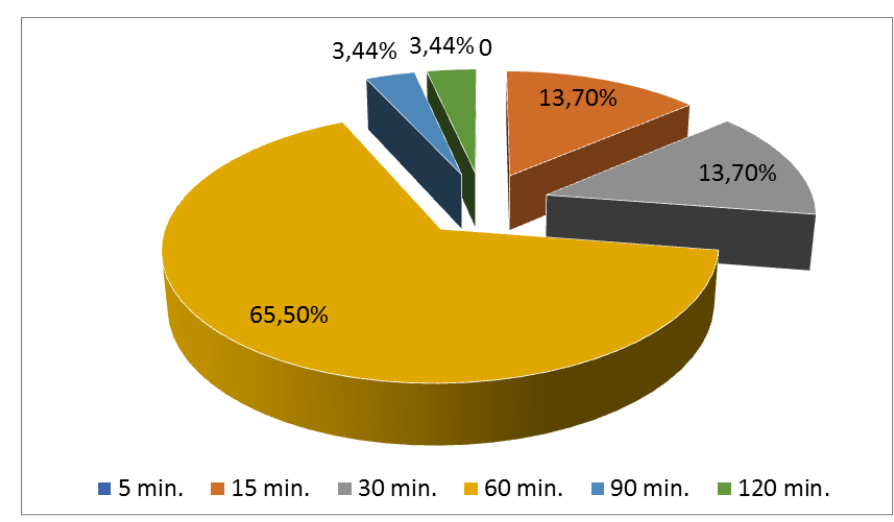

Figura 1. Duración podcast de RNA, n=29. Elaboración propia.

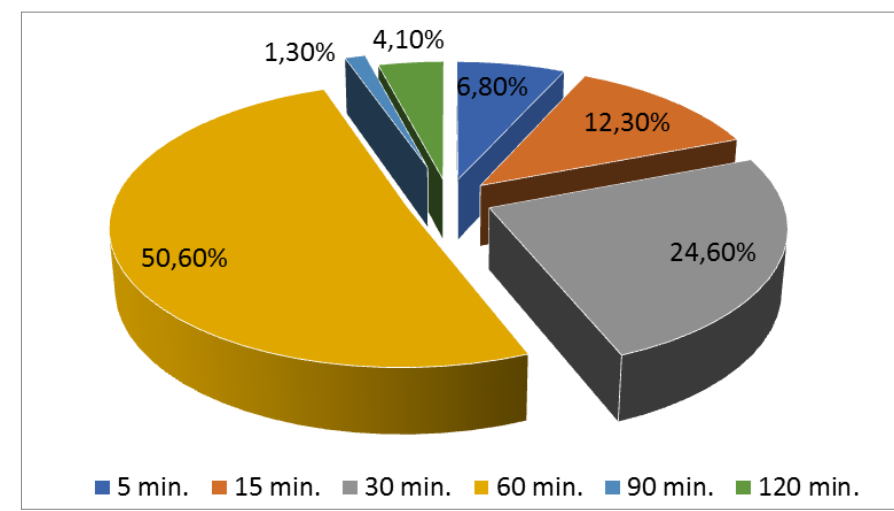

Figura 2. Duración podcast de RNE, n=73. Elaboración propia.

En relación con la duración de los podcasts de las emisoras públicas estudiadas, la oferta se decanta por formatos de mayor duración. Como puede verse en las figuras 1 y 2 , el $65 \%$ de los podcasts identificados en RNA y el 50,6\% en RNE tienen una duración de 60 minutos. No obstante, RNE también apuesta por los formatos de 30 minutos (24,6\%). En el caso de RNA, también se prefiere en segundo lugar podcast de 30 y 15 minutos 
(13,7\%). Ambas emisoras eligen con menos frecuencia las producciones de 90 y 120 minutos.

La periodicidad de publicación de podcast es mayoritariamente semanal en RNA (22 de 29) y diaria en RNE (34 de 73), como se aprecia en la figura 3. RNA no realiza publicaciones de fin de semana y RNE lo hace solo en 8 casos ( $9 \%$ de sus producciones). Ambas emisoras recurren a publicaciones variables, es decir, sin continuidad predeterminada: 6 en el de RNA y 10 en el caso de RNE.

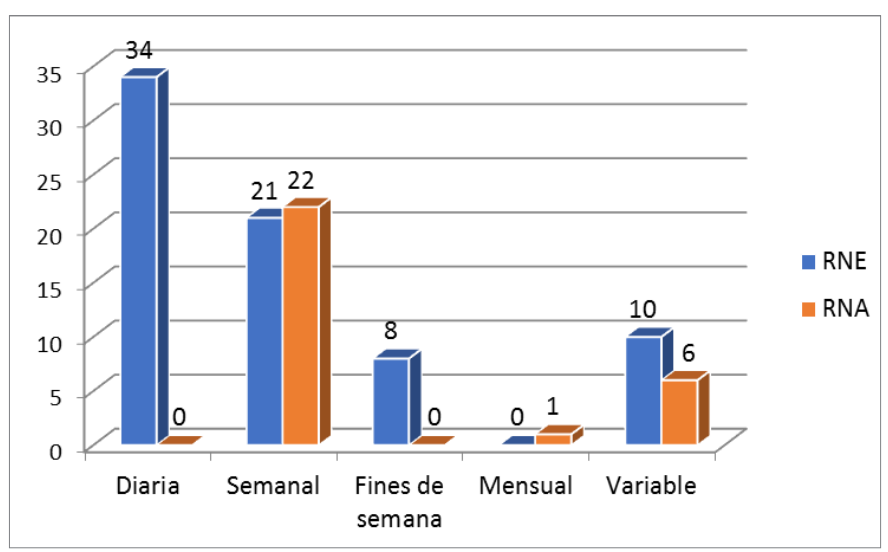

Figura 3. Periodicidad podcasts de RNA, $n=29$ y $R N E, n=73$. Elaboración propia.

Si se distingue la oferta de las emisoras públicas entre ficción y no ficción, se observa que las dos emisoras producen más contenidos de no ficción que de ficción. En RNA solo uno de los podcasts es un radioteatro, pero se trata, quizá, del producto más emblemático de la historia de RNA. Se titula "Las dos carátulas", se emite desde 1950, y en la actualidad registra muy buenos resultados en número de descargas. En 2017, fue el podcast más escuchado de la emisora con 18.222 descargas, y en 2018 estuvo entre los 4 primeros con 45.01610. Además, se publica en formato podcast un segmento de radio relatos de un magacín de la tarde que se titula "Cuentos

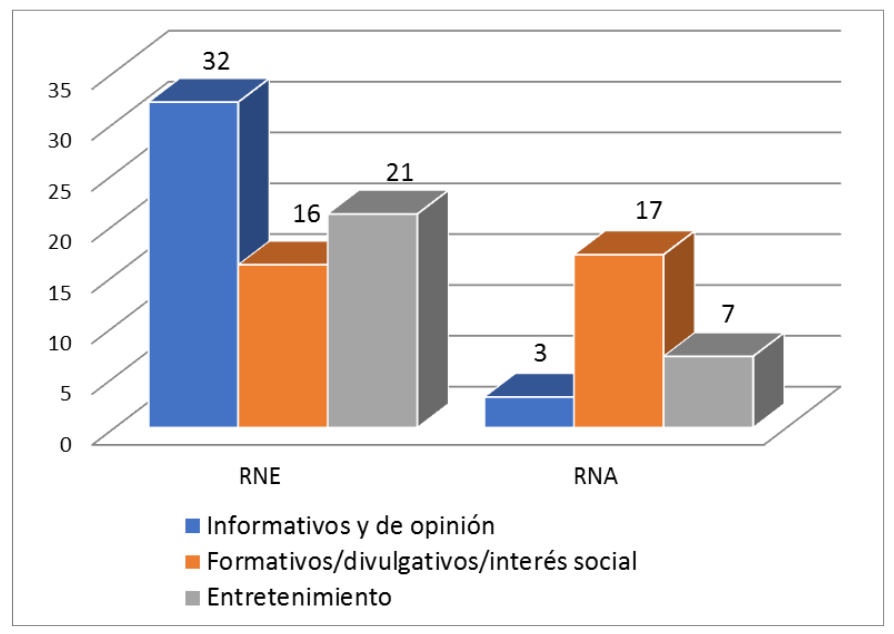

Figura 4. Los podcasts de no ficción de RNA, $n=29$ y $R N E, n=73$. Elaboración propia. dulces, cuentos amargos". RNE cuenta, por su parte, con dos producciones de ficción: "Ficciones sonoras binaurales" y "Litercast".

Entre las producciones de no ficción, RNE elige, sobre todo, los podcasts informativos y de opinión. Casi la mitad de sus publicaciones (46\%) son de contenido informativo y de opinión (32), que a su vez son el tipo de contenido menos frecuente en RNA (3). Para la emisora pública argentina, la mayoría de las producciones (63\%) responde a contenidos formativos, divulgativos y de interés social (17); mientras que para RNE suman el $23 \%$ (16). Los contenidos relacionados con el entretenimiento representan el 31\% para RNE (21) y el 26\% para RNA (7). Así se refleja en la figura 4.

Las diferencias y similitudes que se evidencian entre los contenidos de no ficción, se repiten en el análisis de la utilización de los diferentes géneros radiofónicos, que se recogen en las figuras 5 y 6 . RNE prioriza el género informativo ya que el $42 \%$ de sus podcasts son noticias; mientras RNA produce más formatos de diálogo. El 41\%

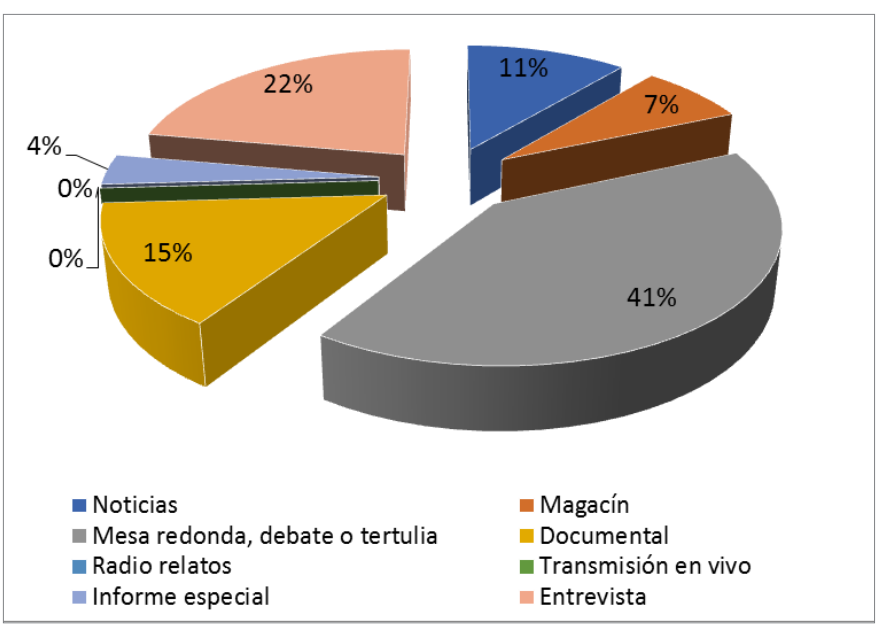

Figura 5. Los géneros radiofónicos y podcasts de RNA, $n=29$. Elaboración propia.

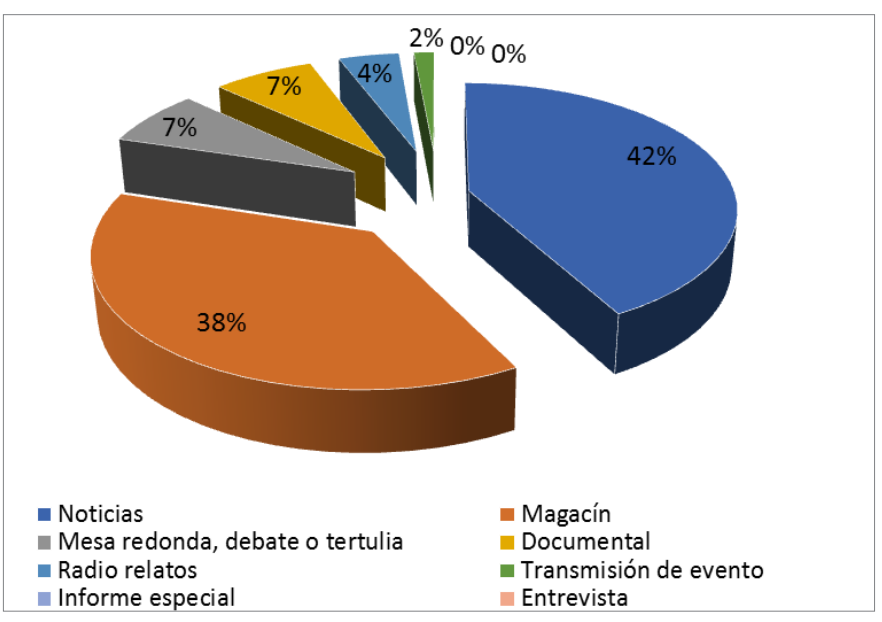

Figura 6. Los géneros radiofónicos y podcasts de RNE, $n=73$. Elaboración propia. 
de los casos registrados de la radio pública argentina son entrevistas, mesas redondas o debates, y solo produce un $11 \%$ de podcasts de noticias.

Por otra parte, RNE elige el magacín en el 38\% de las piezas; mientras que este tratamiento narrativo representa solo el 7\% en RNA. Para esta emisora, en cambio, los géneros radiofónicos más extendidos en sus producciones son la mesa redonda, el debate y la tertulia en el $41 \%$ de los casos; y la entrevista en el 22\%, un género que RNE no utiliza. Hay que señalar también que el 15\% de las producciones de RNA son documentales.

Con respecto a las temáticas, el $44 \%$ de las series de RNA hablan de temáticas relacionadas con el arte y la cultura. En segundo lugar, con el 15\%, aparecen los temas de entretenimiento y famosos y con el $11 \%$ las temáticas de salud y educación (ver figura 7). Con menos frecuencia, los podcasts abordan temáticas sobre esti-

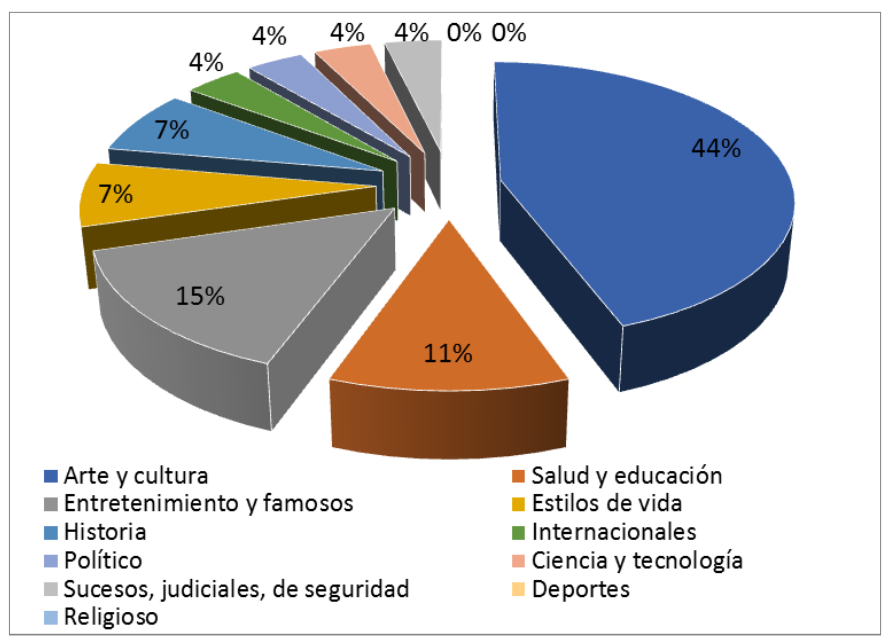

Figura 7. Los temas y los podcasts de RNA, $n=29$. Elaboración propia.

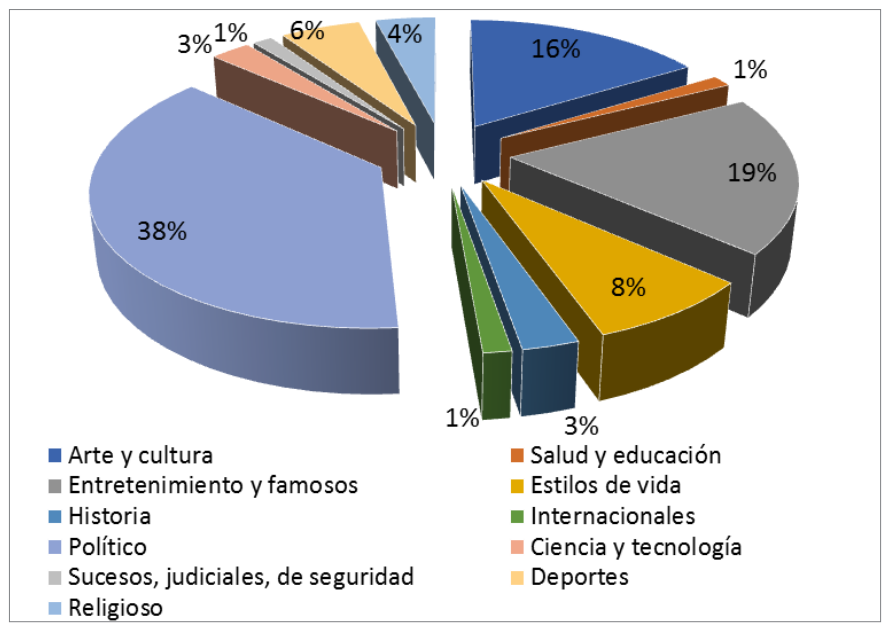

Figura 8. Los temas y los podcasts de RNE, n=73. Elaboración propia. los de vida (7\%), historia (7\%) y temas internacionales (4\%).

La apuesta temática de RNE es totalmente diferente. La emisora pública española dedica el 38\% del contenido en este formato a la política, el 19\% al entretenimiento y el 16\% al arte y la cultura (ver figura 8).

En cuanto a los valores de la radio pública que se expresan a través de sus podcasts, las dos emisoras reflejan el principio de la identidad cultural en la mayoría de las producciones. Se trata del valor más recurrente tanto para RNA (25) como para RNE (53). RNA (16) y RNE (38) también coinciden en el pluralismo como el segundo valor que más se expresa en sus producciones. La diversidad cultural es el tercer valor en presencia para RNA (13) y RNE (29), mientras que en cuarto y quinto lugar figuran la atención a minorías y la igualdad de género. Así se observa en la figura 9.

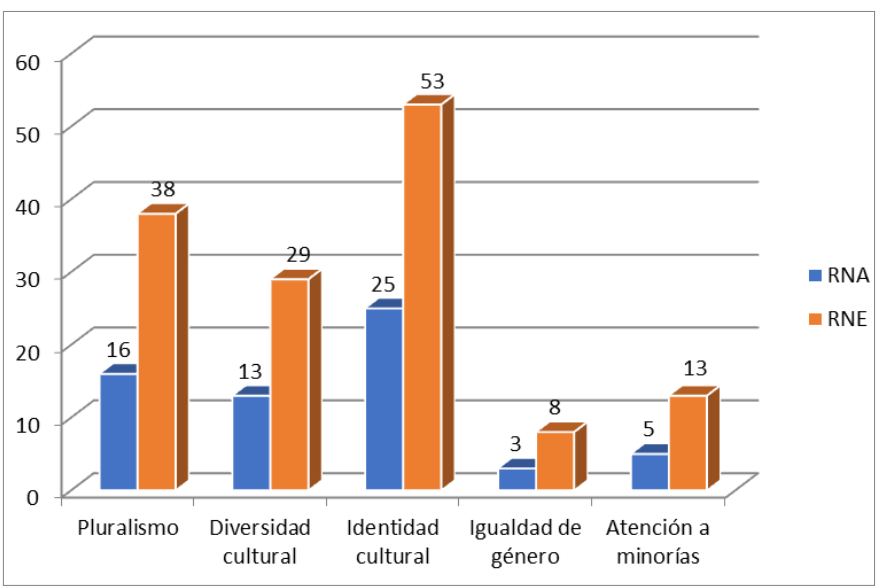

Figura 9. Los principios o valores en los podcasts de RNA, $n=29$ y $R N E, n=73$. Elaboración propia.

Con respecto a los contenidos multimedia asociados, en RNA todos los programas se complementan con la descripción de cada episodio. La mayoría son textos breves, aunque excepcionalmente se cuenta con descripciones más exhaustivas. En todos los casos se utilizan fotografías y en ninguno video. Tres programas cuentan con transcripciones del material. Sólo uno de los programas ofrece un correo de contacto para la audiencia.

En el caso de RNE, se observa que 54 de las 73 series complementan el audio con una breve descripción del contenido. El uso de fotos y videos es limitado, aunque las producciones de la oferta "Solo en podcast" proponen tratamientos multimedia asociados y, en algún caso como "Soñadores", también transmedia. Desde la plataforma web, solo 16 series proponen la posibilidad de interacción con los usuarios. De éstos, 11 ofrecen un 
correo electrónico y 5 un formulario web, que los usuarios casi no utilizan.

Finalmente, ambas emisoras utilizan la distribución multiplataforma para amplificar la visibilidad de sus contenidos, y así incrementar y diversificar audiencia. Con esta estrategia de difusión diversificada, RNE y RNA buscan ampliar el público tradicional que sigue sus emisiones en la antena, y llegar así, sobre todo, a nuevos públicos, sobre todo los más jóvenes.

\section{Conclusiones}

Las emisoras públicas de Argentina y España no han sido pioneras en el impulso de la producción de podcast como modelo transformador de la radio (Martínez y Salgado, 2009; Boninni, 2015). Los inicios de este formato innovador se producen en 2004 y tuvo que pasar más de una década para que RNA en 2018 y RNE en 2019 lanzaran su oferta de podcast nativos y exclusivos para las plataformas digitales. Antes de eso, y de manera no regular, solo se recurre a este formato para empaquetar contenidos bajo demanda producidos para la antena tradicional, o procedentes del archivo histórico, convenientemente editados. En el momento de hacer este estudio, las emisoras generalistas de RNA y de RNE cuentan con una oferta de podcast nativos y exclusivos para la red que crece, pero que aún es poco significativa en el conjunto de sus producciones: 3 de 29 series en RNA y 7 de 73 series en RNE.

Las emisoras públicas generalistas de Argentina y España eligen las producciones propias por encima de las coproducciones o de las producciones externalizadas de terceros, que tienen escaso espacio en su oferta. En este sentido, las dos emisoras públicas rentabilizan el prestigio y visibilidad de los profesionales y programas de sus emisoras tradicionales (presentadores, periodistas, corresponsales, guionistas, productores, realizadores, etc.) para alimentar los contenidos asincrónicos. La presencia en la producción de otras organizaciones e instituciones culturales y sociales no profesionales de la que hablaba Berry (2016) para dar voz a otros grupos de la sociedad es, por el momento, un camino no explorado por la radio pública en el diseño de su oferta de podcast.

Por otra parte, predominan los contenidos ligados a la información y la opinión, la divulgación del arte y la cultura, y el entretenimiento. Esto se refleja en los géneros radiofónicos utilizados y las temáticas abordadas. La noticia es el género más usado por RNE y el menos utilizado por RNA, que prefiere los géneros de diálogo. En cuanto a los temas, la mayoría de los podcasts de RNA abordan temáticas de arte y cultura, mientras que los de RNE hablan de política, en primer lugar, y de entre- tenimiento y famosos, en segundo lugar. La actualidad informativa, cultural y social está presente en todas las producciones, y confirma que la radio pública sigue comprometida con los valores y necesidades de su comunidad (Briggs, 1961).

Desde la perspectiva narrativa, los podcasts de ficción son menos frecuentes. Sin embargo, aun siendo poco numerosos, son producciones cuidadas e innovadoras. Así, destacan los podcast nativos de RNE "Ficciones sonoras binaurales" y "Litercast", que son verdaderos ejercicios experimentales de las posibilidades creativas de la ficción sonora. También las series documentales "Soñadores" de RNE y los grandes reportajes "Nosotros, que fuimos a Malvinas", "Nos" y "Ser iguales" de RNA, exploran diseños sonoros, estructuras dramáticas y montajes diferentes de las producciones de la antena y más propias de las características hipertextuales y transmedia de las plataformas digitales (Pedrero Esteban y García Lastra-Núñez, 2019; Orrantia, 2019).

Aunque las dos emisoras muestran diferencias en los tipos de producción, en las temáticas abordadas y en las apuestas narrativas, coinciden de modo claro en los valores que eligen para promover a través de sus contenidos en formato podcast: identidad cultural, pluralismo y diversidad cultural. Por lo tanto, se puede afirmar que las emisoras generalistas de Radio Nacional Argentina y Radio Nacional de España recurren al podcast para fortalecer su misión de servicio público, ofreciendo contenidos de calidad, diversos y representativos de sus culturas.

Sin embargo, las emisoras públicas tienen aún por delante un doble desafío: trabajar más la segmentación de las audiencias y la atención de las minorías en los procesos de producción y difusión; y ser verdaderos motores de innovación narrativa y experimentación tecnológica a través del podcast (Bonet y Sellas, 2019). De esta forma la radio pública podrá reforzar los valores que animan su razón de ser en interés de los ciudadanos.

\section{Notas al final}

1. Véase, entre otros, los trabajos de Gallo, R. (1991). La radio, ese mundo tan sonoro. Buenos Aires: Corregidor; Pellet Lastra, A (1970). Régimen legal de radio y televisión. Buenos Aires: Ediciones Abeledo-Perrot; y Ulanovsky, C. y Pelayes, S. (2011). La Radio Nacional. Voces de la Historia 1937-2011. Buenos Aires: Ediciones Colihue.

2. Ley 26.522/2009, de 10 de octubre, de los Servicios de Comunicación Audiovisual. Boletín Oficial, núm. 31.756. Disponible en: http://servicios.infoleg.gob.ar/infoleglnternet/ anexos/155000-159999/158649/norma.htm

3. Decreto 1.526/2009, de 21 de octubre, de funcionamiento de la Radio y Televisión Argentina Sociedad del Estado. Disponible en: http://servicios.infoleg.gob.ar/infolegInternet/ anexos/155000-159999/159060/norma.htm 
4. Véase, entre otros, los estudios de Munsó Cabús, J. (1988). Escrito en el aire. 50 años Radio Nacional de España. Madrid: Servicio de Publicaciones RTVE; Balsebre, A (2001). Historia de la radio en España. Volumen 1 (1874-1939). Madrid: Cátedra, p. 445 y ss.; y Faus Belau, Á. (2007). La radio en España (1996-1977). Madrid: Taurus, p. 672-681.

5. Ley $17 / 2006$, de 5 de junio, de la Radio y la Televisión de Titularidad Estatal. Boletín Oficial del Estado, núm. 134, de 6 de junio de 2006. Referencia: BOE-A-2006-9958. Disponible en: http://www. rtve.es/contenidos/corporacion/Ley_17_2006_de_5_de_junio,_ de_\%20la_radio_y_la_television_de_titularidad_estatal._BOE,_consolidado_a_\%201_de_abril_de_2012.pdf

6. Primer mandato-marco a la Corporación RTVE, previsto en el artículo 4 de la Ley 17/2006, de 5 de junio, de la Radio y la Televisión de Titularidad Estatal y aprobado por las Cortes Generales de Estado. Boletín Oficial de las Cortes Generales, núm. 470, de 18 de diciembre de 2007. Disponible en: http://www.rtve.es/contenidos/ corporacion/MANDATO_MARCO_DE_LA_CORPORACION.pdf

7. Principios que regirán la Nueva Ley de Comunicaciones emergentes, redactados por la comisión para la elaboración del proyecto de reforma, actualización y unificación de las leyes 26.522 y 27.078 . Disponible en: https://www.enacom.gob.ar/nueva-ley-comunicaciones/17-principios-de-la-nueva-ley_n1371

8. Ley $7 / 2010$, de 31 de marzo, General de la Comunicación Audiovisual. Disponible en: http://www.boe.es/boe/dias/2010/04/01/ pdfs/BOE-A-2010-5292.pdf

9. Principios Básicos de Programación, aprobados por el Consejo de Administración de la Corporación RTVE el 13 de junio de 2007. Disponible en: http://www.rtve.es/contenidos/documentos/Principios_basicos_de_la_programacion_de_RTVE.pdf

10. Cfr. Informe de Gestión 2016 - 2018 de Radio y Televisión Argentina S.E. Disponible en versión papel en RTA S.E. (RNA).

\section{Referencias}

Alfonso, A. y Pérez Tornero, J.M. (1998). Hacia un Sistema de Radiodifusión de Servicio Público. PNUD y UNESCO.

AIMC (2019). Estudio general de medios. 30 ola de 2019. https://www. aimc.es/blog/entrega-resultados-egm-3a-ola-2019/

Bardin, L. (1996). Análisis de contenido. Akal.

Berry, R. (2016). Podcasting: Considering the evolution of the medium and its association with the word 'radio. The Radio Journal International Studies in Broadcast and Audio Media, 14(1), 7-22. https://doi. org/10.1386/rjao.14.1.7_1

Bonet, M. y Sellas, T. (2019). Del flujo al stock: el programador radiofónico ante la gestión del catálogo digital. El profesional de la información, 28 (1), 1-8. https://doi.org/10.3145/epi.2019.ene.09

Boninni, T. (2015). The Second Age of podcasting: Reframing podcasting as a new digital mass medium. Quaderns del CAC, 41, 21-30. https://www.academia.edu/14504222/The_Second_Age_ of_Podcasting_reframing_Podcasting_as_a_New_Digital_Mass_ Medium

Briggs, A. (1961). The history of the broadcasting in the United Kingdom. Volumen 1: The birth of broadcasting. Oxford University Press.

Espada, A. (2018). Nuevos modelos radiofónicos: las redes de podcast en Argentina: producción, distribución y comercialización de la radio on demand. Question, 1(59), e081. https://doi. org/10.24215/16696581e081

European Broadcasting Union (2012). Empowering Society: A Declaration on the Core Values of Public Service Media. https://www.ebu.ch/ about/public-service-media
Gallego-Pérez, J. I. (2010). Podcasting: Nuevos modelos de distribución para los contenidos sonoros. UOC.

García-Marín, D. y Aparici, R. (2018). Nueva comunicación sonora. Cartografía, gramática y narrativa transmedia del podcasting. El Profesional de la Información, 27(5), 1071-1081. https://doi. org/10.3145/epi.2018.sep.11

González, M. J. y Salgado, C. (2009). Redes de participación e intercambios en la radio pública: los podcasting. Comunicar, 17(33), 45-54. https://doi.org/10.3916/c33-2009-02-004

Lewis, P., y Booth, J. (1992). El Medio Invisible. Radio pública, privada, comercial y comunitaria. Paidós Comunicación.

Martínez- Costa, M. P. y Prata, N. (2017). La radio en busca de su audiencia: hacia una escucha diversificada y multiplataforma. Intercom- Revista Brasileira de Ciências da Comunicação, 40(3), 109-128. https://doi.org/10.1590/1809-5844201737

Martínez- Costa, M. P. (1995). Factores de transformación de la radio europea. De la estructura de los monopolios al pluralismo tecnológico. Comunicación y sociedad, 8(2), 113-140. https://doi. org/10.15581/003.8.2.113-140

Moreno, E., Martínez-Costa, M.P. y Amoedo, A. (2009). Radio and the Web: Communication Strategies of Spanish Radio Networks on the Web (2006-2008). Observatorio (OBS*) Journal, 10, 121-137. https:// doi.org/10.7458/obs332009288

Murciano, M. (2006). Las políticas de comunicación ante los retos del nuevo milenio: pluralismo, diversidad cultural, desarrollo económico y tecnológico y bienestar social. Zer, 20, 371-398. https://www.ehu. eus/ojs/index.php/Zer/article/view/3778

Murtha, J. (2016). WNYC is leading public radio's transition to public podcasting". Columbia Journalism Review. https://www.cjr.org/ the_feature/wnyc_public_radio_podcast.php\#targetText=When\%20 it $\% 20$ comes $\% 20$ to\%20money,most $\% 20$ comparable $\% 20$ public $\% 20$ radio\%20broadcasters

Newman, N., Flechter, R., Levy, D. A. y Nielsen, R. K. (2016). Digital News Report. Reuters Institute for the Study of Journalism. https:// reutersinstitute.politics.ox.ac.uk/sites/default/files/research/files/ Digital\%2520News\%2520Report\%25202016.pdf

Niles, R. (2005). Will NPR's podcasts birth a new business model for public radio? Online Journalism Review. http://www.ojr.org/willnprs-podcasts-birth-a-new-business-model-for-public-radio

Orrantia, A. (2019). Diez claves para contar buenas historias en podcast. 0 cómo producir contenidos en un entorno digital cambiante. Editorial UOC.

Pedrero Esteban, L. M. y García Lastra-Nuñez, J. M. (2019). La transformación digital de la radio. Diez claves para su comprensión profesional y académica. Tirant Humanidades.

Pérez, J. y Gallego, I. (2012). Podcasting in Spain: A new business model or a reflection of traditional radio? Radio Journal: International Studies in Broadcast \& Audio Media, 10(1), 23-34. https://doi. org/10.1386/rjao.10.1.23_1

Pérez Alaejos, M. y López Merayo, A. (2013). Entre ondas y bits: el podcasting en las redes nacionales de radio españolas. Comunicação Midiática, 8(3), 181-202.

Pérez-Alaejos, M. Pedrero-Esteban, L. M., y Leoz-Aizpuru, A. (2018). La oferta nativa de podcast en la radio comercial española: contenidos, géneros y tendencias. Fonseca, Journal of Communication, 17, 91-106. https://doi.org/10.14201/fjc20181791106 
UNESCO (2001). Declaración universal de la UNESCO sobre la diversidad cultural. http://portal.unesco.org/es/ev.phpURL_ ID=13179\&URL_DO=DO_TOPIC\&URL_SECTION=201.htmL

UNESCO (2014). Indicadores UNESCO de Cultura para el Desarrollo (IUCD). https://es.unesco.org/creativity/sites/creativity/files/iucd_ manual_metodologico_1.pdf

UNESCO (2019). Tesauro. http://vocabularies.unesco.org/browser/ thesaurus/es/page/concept260

Wired (2005, 6 de diciembre). Oxford Dictionary Names "Podcast" 2005 Word of the Year. https://www.wired.com/2005/12/oxford-dictiona

World Radio and Television Council (2001). Public broadcasting: Why? How? https://unesdoc.unesco.org/ark:/48223/pf0000124058

Yin, R. K. (2014). Case Study Research. Design and Methods. Sage.

\section{CV}

María del Pilar Martínez-Costa. Es Doctora en Comunicación Pública por la Universidad de Navarra, Pamplona (España). Trabaja en la Facultad de Comunicación de la Universidad de Navarra donde imparte la asignatura Géneros y programas de radio y Comunicación radiofónica. Actualmente es Directora del Departamento de Proyectos Periodísticos de la misma Universidad. El desarrollo de su carrera universitaria se ha centrado en el estudio de la interrelación entre la radio como medio de comunicación, los géneros radiofónicos y la tecnología de difusión, en tanto ésta última modifica los modelos de producción, difusión, escucha y comercialización tradicional del medio. https://www.unav. edu/web/facultad-de-comunicacion/profesores/detalle-profesor?investigadorld $=39527$
María José Müller. Es Doctora en Comunicación por la Universidad Austral, Buenos Aires (Argentina). Es profesora a cargo de la asignatura Lenguaje sonoro de la Facultad de Comunicación de la Universidad Austral. Ha dedicado su carrera como investigadora al periodismo radiofónico, el análisis de la programación de la radio tradicional y al sonido en el entorno digital. https:// www.austral.edu.ar/posgrados-comunicacion/docentes/cuerpo-academico/lic-maria-jose-muller

Marta Villar. Es licenciada en Comunicación Social por Universidad F.A.S.T.A. y completó el curso de la Maestría en Gestión de Contenidos de la Universidad Austral. Es profesora adjunta de Estructura y crítica de la información de la Facultad de Comunicación de la Universidad Austral y profesora a cargo de Mapa de medios y mercado de las comunicaciones de la Facultad de Periodismo y Comunicación de la Universidad F.A.S.T.A. Paralelamente, es productora y asesora en gestión de contenidos. Actualmente trabaja en la Secretaría de Medios Públicos de la Nación argentina. http:// www.linkedin.com/in/martavillar

\section{осм \\ Observatorio de Cibermedios}

\section{https://observatoriocibermedios.upf.edu/}

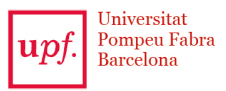

Departamento de Comunicación
Grupo DigiDoc

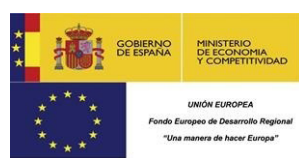

El Observatorio de Cibermedios es una producción del Grupo de Investigación en Documentación Digital y Comunicación Interactiva (DigiDoc) del Departamento de Comunicación de la Universitat Pompeu Fabra.

El Observatorio de Cibermedios (OCM) forma parte del proyecto del Plan Nacional "Creación y contenido interactivo en la comunicación de información audiovisual: audiencias, diseño, sistemas y formatos". CS02015-64955-C4-2-R (MINECO/ FEDER), Ministerio de Economía y Competitividad (España). 